\title{
Imbalance between Apoptosis and Proliferation Causes Late Radiation Damage of Salivary Gland in Mouse
}

\author{
M. MUHVIC-UREK ${ }^{1}$, M. BRALIC ${ }^{2}$, S. CURIC ${ }^{3}$, S. PEZELJ-RIBARIC ${ }^{1}$, \\ J. BORCIC ${ }^{1}$ J. TOMAC ${ }^{2}$ \\ ${ }^{1}$ Department of Prosthodontics, School of Dental Medicine, University of Rijeka, Rijeka, Croatia, \\ ${ }^{2}$ Department of Histology and Embryology, Faculty of Medicine, University of Rijeka, Rijeka, \\ Croatia, ${ }^{3}$ Department of General Pathology and Pathomorphology, Faculty of Veterinary \\ Medicine, University of Zagreb, Zagreb, Croatia
}

Received December 8, 2004

Accepted February 25, 2005

On-line available April 26, 2005

\begin{abstract}
Summary
Severe xerostomia is a common late radiation consequence, which occurs after irradiation of head and neck malignancies. The aim of the present study was to analyze apoptosis and proliferation and their relationship during the late post-irradiation phase. C57BL/6 mice were locally irradiated in head and neck region with a single dose of 7.5 or $15 \mathrm{~Gy}$ and their submandibular glands were collected at 40 and 90 days after irradiation. To identify apoptotic cells, the TUNEL method was employed and immunohistochemistry with proliferating cell nuclear antigen (PCNA) was used for detecting proliferation. Histological changes at day 40 were mild in contrast to day 90 when glands of irradiated mice showed severe atrophy, vacuolization and mononuclear infiltration. Acinar cells, granular and intercalated duct cells of mice irradiated with 7.5 and 15 Gy expressed higher apoptotic index than cells of non-irradiated, control glands at both examined time points. At 40 days, a higher proliferation index in granular and intercalated duct cells was detected only in group irradiated with $7.5 \mathrm{~Gy}$. At 90 days, proliferation index for all cell types in both irradiated groups was similar to the controls. According to our results, the imbalance between apoptosis and proliferation caused by X-irradiation may be the reason for gland impairment during the late post-irradiation phase.
\end{abstract}

Key words

Irradiation $\bullet$ Salivary glands $\bullet$ Late post-irradiation phase $\bullet$ Apoptosis $\bullet$ Proliferation

\section{Introduction}

Radiotherapy plays an important role in the treatment of head and neck tumors. Unfortunately, too many patients whose salivary glands are irradiated during treatment for their cancer often results in life-long severe xerostomia ("dry mouth"). Reduction in salivary flow per $s e$ is not life-threatening, but deterioration of dental and oral health has significant impact on the quality of their life (Guchelaar et al. 1997, Taylor and Miller 1999, Taylor 2003).

Numerous studies have demonstrated that radiation-induced impairment of salivary glands could be divided into two phases: short-term crisis followed by 
recovery period and late deterioration phase (Coppes et al. 1997, Nagler and Laufer 1998, Nagler 2001, 2002, Muhvic-Urek et al. 2005). In rodents, the chronic radiation damage to salivary glands is fully developed and stabilized within 60-90 days after radiation treatment (Sodicoff et al. 1978, Dorr 1998).

The complex relationship among cell proliferation, differentiation and apoptosis is a cardinal feature in the maintenance of normal architecture and function of submandibular gland. Enhanced apoptosis of acinar cells is hypothesized to be one of the major causes of salivary gland impairment and it can be induced with DNA damaging agents such as radiation (Baehrecke 2002, Limesand et al. 2003).

One can speculate that gland proliferation is increased in an attempt to overcome the irradiation damage. We therefore investigated expression of the proliferating cell nuclear antigen (PCNA) in irradiated glands. Since PCNA manifests itself mostly during S-phase of the cell cycle it is widely used as a marker of proliferation (Girod et al. 1998, Actis et al. 2002).

The purpose of this study was to analyze the relationship between apoptosis and proliferation in acinar, granular duct and intercalated duct cells during late (40 days) and prolonged (90 days) post-irradiation period.

\section{Methods}

Male C57BL/6 mice aged 8-10 weeks were randomly divided into three groups: (I) sham irradiated control group; (II) 7.5 Gy irradiated; and (III) 15 Gy irradiated. The mice were intraperitoneally anesthetized with sodium pentobarbital $(40 \mathrm{mg} / \mathrm{kg}$ b.w.), fixed in a plastic mould and locally irradiated in the head and neck regions with $6 \mathrm{MV} \mathrm{X}$-rays from a medical linear accelerator (Mevatron MD-2, Siemens, Medical Laboratories Inc., USA) with a single dose of $7.5 \mathrm{~Gy}$ $(\mathrm{n}=15)$ or 15 Gy $(\mathrm{n}=15)$ (Nagler 1998, Nagler et al. 1998). Irradiation was performed by a standard source to surface distance (SSD) of $100 \mathrm{~cm}$. Radiation field size was $\mathrm{x}=15 \mathrm{~cm}, \mathrm{y}_{1}=0 \mathrm{~cm}, \mathrm{y}_{2}=3 \mathrm{~cm}$ and a dose rate was $191 \mathrm{cGy} / \mathrm{min}$. Prior to the irradiation beam, calibration in solid water phantom was performed using Farmer type 0.6 cc ionization chamber with PTW Unidos dosimeter. Control animals $(n=15)$ were anesthetized, fixed and sham-irradiated. The Ethical Committee of the Medical Faculty at University of Rijeka approved all procedures using mice.

Submandibular glands were analyzed at 40 and
90 days after irradiation, i.e. at two time points that represent long and extended post-irradiation periods (Nagler 1998, Nagler et al. 1998). The excised submandibular glands were immediately fixed in $4 \%$ paraformaldehyde and processed for paraffin embedding according to standard procedure. Serial sections $2 \mu \mathrm{m}$ thick were cut and stained with hematoxylin and eosin (H\&E). Nuclear aberrations were examined at $600 \mathrm{x}$ magnification using light microscope (Olympus, Japan). Histopathological criteria for apoptotic cells were shrunken cells with condensation of chromatin forming dense stained, sharply delineated granular masses.

To detect apoptotic cells the TUNEL method was performed using In Situ Cell Death Detection KitPOD, (Roche Diagnostics GmbH, Germany) (Macluskey et al. 2000). The sections were incubated with terminal deoxynucleotidyl transferase (TdT) and fluorescein deoxyuridine triphosphate (dUTP) without proteinase $\mathrm{K}$ pretreatment. After phosphate buffer saline (PBS) rinsing, anti-fluorescein-peroxidase antibody was applied and the reaction was visualized by 3,3'-diaminobenzidine (DAB). Sections were counterstained with hematoxylin. Control sections were incubated with distilled water in the absence of TdT.

To examine proliferating cells, sections were incubated with anti-PCNA monoclonal antibody (DAKO, USA) (Roos et al. 1993), followed by staining with biotinylated rabbit anti-mouse polyclonal antibody (DAKO, USA) and the streptavidin-biotin-peroxidase complex (Boehringer, Germany). As a chromogen 3-amino-9-ethyl-carbazol substrate (AEC-SubstrateChromogen, DAKO, USA) was used. PBS was substituted for the primary antibody as negative control. Hematoxylin was used for counterstaining.

The apoptotic and proliferation indexes were calculated for each group (Macluskey et al. 2000). Labeling index represented the apoptotic/proliferating cells as a percentage of the specific cell type. Five coded sections stained with PCNA and TUNEL were randomly chosen from each animal. Approximately 1000 cells from each cell population (acinar cells, granular duct cells, intercalated duct cells) were counted by two observers (MM-U, MB) at a magnification of 400x (Olympus, Japan), and the percentage of PCNA and TUNEL positive cells was calculated. Striated ducts were omitted from the study since too few of them were examined to provide useful information. The labeling index for each group was obtained by averaging the percentages of all animals, and the mean value \pm standard error of mean (SEM) were 
determined for the control, 7.5 and 15 Gy irradiated group. The comparison between experimental and control data was made by two-way analysis of variance, followed by Tukey's honestly significant difference (HSD) post hoc test, with $\mathrm{P}<0.05$ as statistically significant.
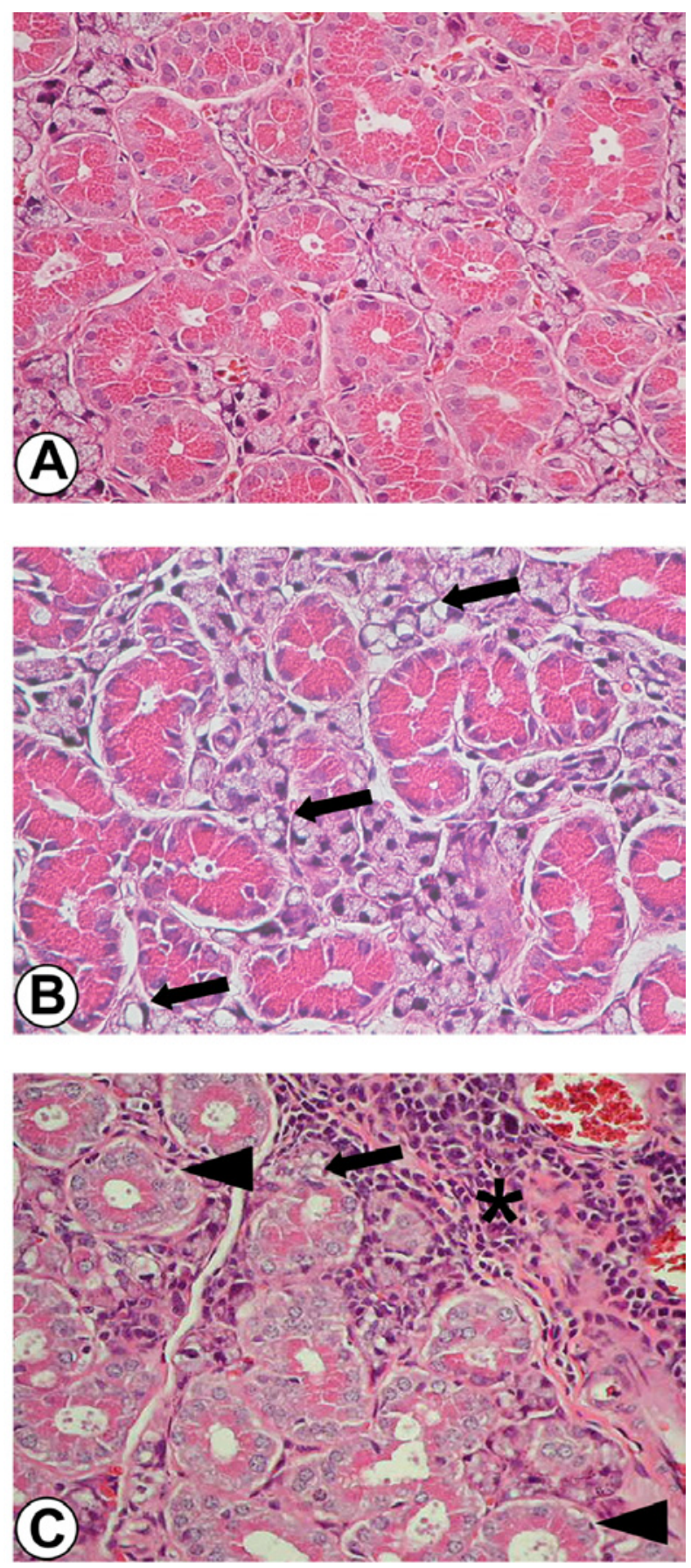

Fig. 1. Histopathological changes in submandibular gland after irradiation. Normal appearances of acinar cells in control animal (A), whereas in gland irradiated with $15 \mathrm{~Gy}$ at 40 days after irradiation (B) and at 90 days after irradiation (C) vacuolization $(\boldsymbol{\leftarrow})$, condensated nuclei $(\mathbf{4})$ and mononuclear infiltration (*) is observed. H\&E. Magnification x400.

\section{Results}

\section{Survival}

All animals in the control group survived the whole experimental period as well as animals irradiated with 7.5 Gy. In the group irradiated with $15 \mathrm{~Gy}, 3$ mice died within 2 weeks during the acute post-irradiation phase.

\section{Histological observation}

Histological observation of control animals showed normal morphology, i.e. ducts widely separated by crowded acini (Fig. 1A) while mild histological changes were observed in glands of irradiated animals with 7.5 and 15 Gy at 40 days after irradiation. Only vacuolization of acinar cells was detected and no pathological changes in the ducts and interstitium were present (Fig. 1B). Moreover, no significant difference between two irradiation doses was observed in tissue morphology.

At 90 days, submandibular glands of irradiated animals showed acinar atrophy, reduction in the number and severe vacuolization of acinar cells. Changes were more intensive in glands irradiated with higher radiation dose. In animals treated with 7.5 Gy granular duct cells were unaffected, but in animals irradiated with 15 Gy granular duct cells were often degenerated and desquamated. In interstitium of 15 Gy irradiated glands small edema was present, but the most remarkable change concerned disseminated mononuclear infiltration observed in all irradiated glands (Fig. 1C).

\section{Apoptosis and proliferation}

In the submandibular gland of control animals, a small number of apoptotic cells was observed in acinar cells $(0.06 \%)$, granular duct cells $(0.36 \%)$ and intercalated duct cells $(0.3 \%)$. At 40 days after irradiation, higher apoptotic activity was noted in all investigated cell compartments in both irradiated groups. Apoptotic activity in irradiated glands decreased from 40 to 90 days, but it remained above control levels. Only in the population of acinar cells irradiated with 15 Gy significantly higher apoptotic activity was observed even at day 90 (Figs 2A and 3).

Submandibular gland of control animals exhibited low proliferative activity in all gland compartments: acinar cells (2\%), granular duct cells $(6.42 \%)$ and intercalated duct cells $(2.25 \%)$. At 40 days after irradiation, labeling index for granular and 
intercalated duct cells in mice irradiated with 7.5 Gy was higher than that of acinar cells. In addition, labeling index for both duct cells was significantly higher than in control mice, while mice irradiated with 15 Gy exhibited labeling index similar to control level. At 90 days after irradiation in all gland compartments (acinar cells, intercalated and granular duct cells) the proliferative activity in irradiated mice was similar to the control, sham irradiated group (Figs 2B and 4).
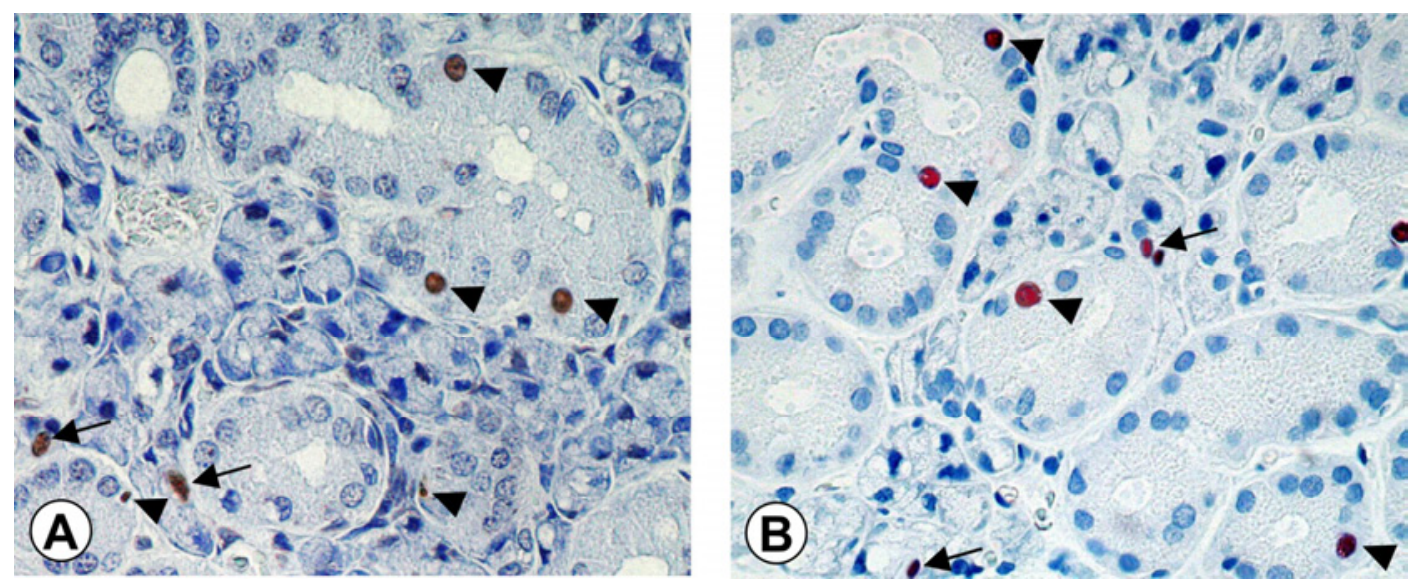

Fig. 2. Example of TUNEL (A) and PCNA (B) labeling in salivary gland tissue after irradiation. Apoptotic TUNEL positive cells have brown nuclei, whereas proliferative PCNA positive cells have red nuclei. Magnification $\times 400$.

A

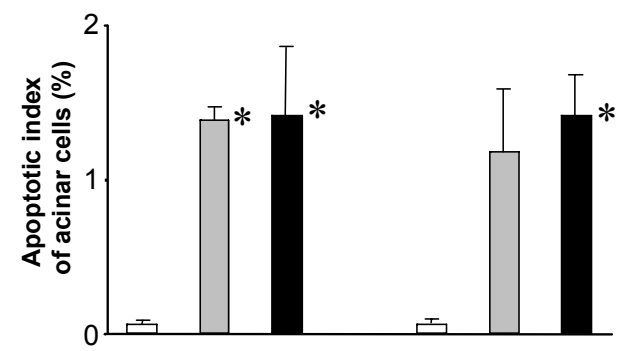

B

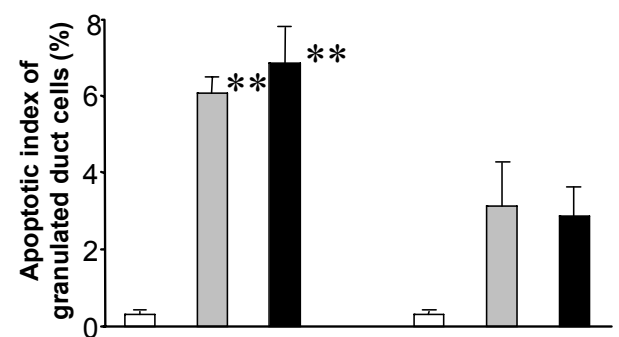

C

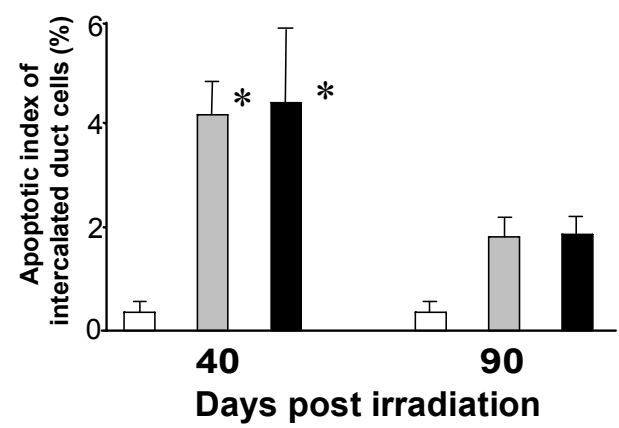

Control

IR 7.5 Gy

IR 15 Gy

Fig. 3. Apoptotic index of individual parenchymal cell types (mean \pm SEM) in submandibular gland after irradiation. (A) Acinar cells, (B) Granular duct cells, (C) Intercalated duct cells. * denotes statistical significance of $\mathrm{P}<0.05 ; * *$ denotes statistical significance for $\mathrm{P}<0.001$.
A

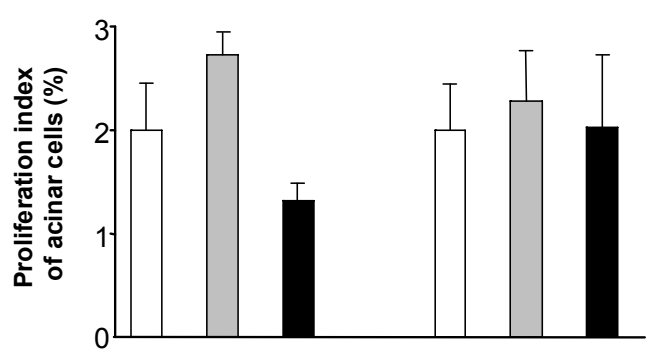

B

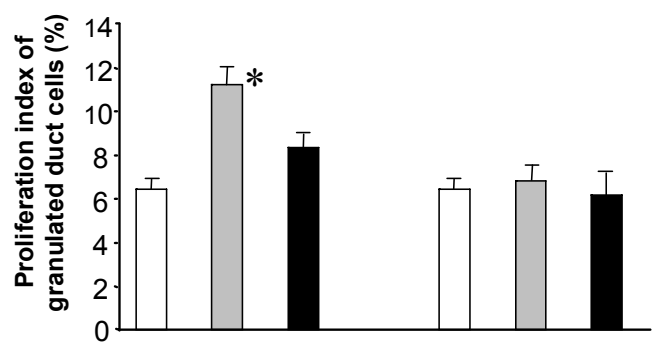

C

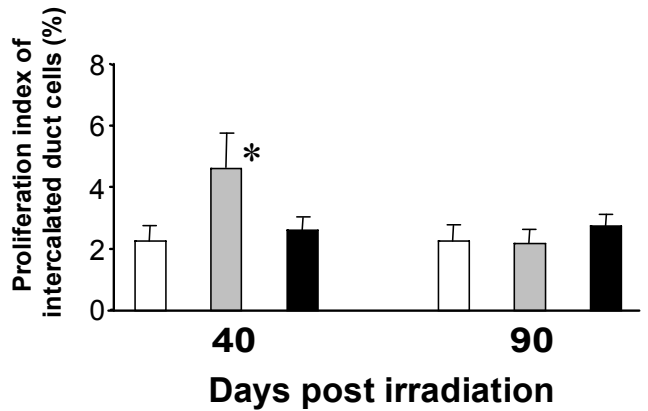

Control

IR 7.5 Gy

IR 15 Gy

Fig. 4. Proliferation index of individual parenchymal cell types (mean \pm SEM) in submandibular gland after irradiation. (A) Acinar cells, (B) Granular duct cells, (C) Intercalated duct cells. * denotes statistical significance for $\mathrm{P}<0.05$. 


\section{Discussion}

The mechanism of salivary gland pathology induced by radiation is not clearly understood and no adequate prevention and treatment is yet available. Late tissue response to radiotherapy is regarded as more important than the acute effects because of their progressive and irreversible character. Parenchymal cells, vascular endothelium and fibroblasts are considered as target cells for irradiation-induced damage (Dorr and Hendry 2001, Paris et al. 2001). We analyzed the apoptotic and proliferation index in parenchymal cells since their loss lead to functional impairment of salivary glands and hyposalivation (xerostomia) that are major symptoms of head and neck radiotherapy. Mouse submandibular gland is formed of parenchymal cells organized in acini and secretory ducts (intercalated, granular and striated) that converge to form the excretory ducts. Since cells of salivary glands have slow turnover rates, one could expect they would be relatively radioresistant. On the contrary, they are extremely radiosensitive. It is known that radiosensitivity is greatest in serous secretory cells followed by mucous secretory cells whereas ductal cells appeared to be relatively radioresistant.

There is convincing evidence that ionizing radiation can induce apoptosis (Langley et al. 1993, Bump et al. 1994, Roos 1999, Belka et al. 2004). It is believed that apoptosis plays a major role only during acute post-irradiation damage (Guchelaar et al. 1997), but we have observed significantly higher apoptotic index in irradiated animals during the late post-irradiation phase. Our results lead to assumption that irradiation is responsible for sublethal DNA damage that becomes manifest during late post-irradiation phase. The damaged cell is detected on the cell cycle checkpoint and instead entering mitosis it is subjected to apoptosis (Roos 1999, Nagler 2002). To our knowledge no investigation using the TUNEL method on submandibular glands of irradiated mice has been performed. Denny and Denny (1999) investigated dynamics of parenchymal cell apoptosis in normal mouse submandibular gland by the same method. These authors have found apoptotic index for acinar and other cell types similar to those we obtained for non-irradiated control mice.

The highest proliferation index was detected at the late time point (40 days after irradiation) in group irradiated with $7.5 \mathrm{~Gy}$, while control and $15 \mathrm{~Gy}$ irradiated animals exhibit similar values. We have evidence that animals irradiated with lower radiation dose exhibit higher proliferative capacity. At the same time both ductal cells exhibited higher proliferative capacity in contrast to acinar cells whose proliferative activity was similar to the control level. Peter et al. (1994) investigated the early post-irradiation phase and they observed the highest proliferative activity of intercalated duct cells and suggested intercalated duct cells as stem cells.

At 40 days after irradiation mild microscopic changes (vacuolization) in the irradiated gland were noted. We have confirmed the findings of Vitolo et al. (2004), who observed discrete vacuolization in acinar cells in mice irradiated with $15 \mathrm{~Gy}$. We have evidence that in the late deterioration phase postponed effects of irradiation emerge and aggravate gland morphology. Our observation is in accordance with the results of studies performed on rats, rabbits and primates (including humans) (Stephens et al. 1986, Ahlner et al. 1994, Price et al. 1995, Nagler 2001, 2002). Inflammatory infiltration detected in primates and rabbits were also found in mice (Taylor and Miller 1999). Since ionizing radiation can induce apoptosis as well as necrosis (Guchelaar et al. 1997), necrosis could be the reason for salivary gland's inflammatory infiltration as we have also observed.

We also demonstrated that the proliferation index was similar as control values during extended postirradiation period. At the same time significantly higher apoptosis was detected in acinar cells irradiated with $15 \mathrm{~Gy}$. In other cell types, apoptosis was above control levels implicating that proliferation was not sufficient to sustain normal architecture of the gland.

We conclude that elevated apoptosis in the irradiated gland is major cause of imbalance between cell production and cell loss. Further research concerning the modulation of apoptotic-signaling pathway may hopefully improve the therapeutic potential and reduce late time sequelae in irradiated salivary glands.

\section{Acknowledgements}

We thank S. Jonjic for critical comments during the manuscript preparation. 


\section{References}

ACTIS AB, LAMPE PD, EYNARD AR: Cellular basis and clinical implications of biological markers in salivary tissues: their topological distribution in murine submandibular gland. Oral Oncol 38: 441-9, 2002.

AHLNER BH, HAGELQVIST E, LIND MG, RUDEN BI: Irradiation of rabbit submandibular glands. Histology and morphometry after 15 Gy. Acta Otolaryngol 113: 210-219, 1993.

BAEHRECKE EH: How death shapes life during development. Nat Rev Mol Cell Biol 3: 779-787, 2002.

BELKA C, JENDROSSEK V, PRUSCHY M, VINK S, VERHEIJ M, BUDACH W. Apoptosis-modulating agents in combination with radiotherapy-current status and outlook. Int J Radiat Oncol Biol Phys 58: 542-554, 2004.

BUMP EA, BRAUNHUT SJ, PALAYOOR ST, MEDEIROS D, LAI LL, CERCE BA, LANGLEY RE, COLEMAN CN: Novel concepts in modification of radiation sensitivity. Int J Radiat Oncol Biol Phys 29: 249-253, 1994.

COPPES RP, ZEILSTRA LJ, VISSINK A, KONINGS AW: Sialogogue-related radioprotection of salivary gland function: the degranulation concept revisited. Radiat Res 148: 240-247, 1997.

DENNY PC, DENNY PA: Dynamics of parenchymal cell division, differentiation, and apoptosis in the young adult female mouse submandibular gland. Anat Rec 254: 408-417, 1999.

DORR W: Radiobiological models of normal tissue reactions. Strahlenther Onkol 174: 4-7, 1998.

DORR W, HENDRY JH: Consequential late effects in normal tissues. Radiother Oncol 61: 223-231, 2001.

GIROD SC, PFEIFFER P, RIES J, PAPE HD: Proliferative activity and loss of function of tumour suppressor genes as 'biomarkers' in diagnosis and prognosis of benign and preneoplastic oral lesions and oral squamous cell carcinoma. Br J Oral Maxillofac Surg 36: 252-260, 1998.

GUCHELAAR HJ, VERMES A, MEERWALDT JH: Radiation-induced xerostomia: pathophysiology, clinical course and supportive treatment. Support Care Cancer 5: 281-288, 1997.

LANGLEY RE, PALAYOOR ST, COLEMAN CN, BUMP EA: Modifiers of radiation-induced apoptosis. Radiat Res 136: 320-326, 1993.

LIMESAND KH, BARZEN KA, QUISSELL DO, ANDERSON SM: Synergistic suppression of apoptosis in salivary acinar cells by IGF1 and EGF. Cell Death Differ 10: 345-355, 2003.

MACLUSKEY M, CHANDRACHUD LM, PAZOUKI S, GREEN M, CHISHOLM DM, OGDEN GR, SCHOR SL, SCHOR AM: Apoptosis, proliferation, and angiogenesis in oral tissues. Possible relevance to tumor progression. J Pathol 191: 368-375, 2000.

MUHVIC-UREK M, BRALIC M, TOMAC J, BORCIC J, UHAC I, GLAZAR I, ANTONIC R, FERRERI S: The early and late effects of X-irradiation on submandibular gland. A morphological study in mice. accepted by Arch Med Res 36: 339-343, 2005.

NAGLER RM: Short- and long-term functional vs morphometrical salivary effects of irradiation in a rodent model. Anticancer Res 18: 315-320, 1998.

NAGLER RM: Extended-term effects of head and neck irradiation in a rodent. Eur J Cancer 37: 1938-1945, 2001.

NAGLER RM: The enigmatic mechanism of irradiation-induced damage to the major salivary glands. Oral Dis 8: 141$146,2002$.

NAGLER RM, LAUFER D: Protection against irradiation-induced damage to salivary glands by adrenergic agonist administration. Int J Radiat Oncol Biol Phys 40: 477-481, 1998.

NAGLER RM, BAUM BJ, MILLER G, FOX PC: Long-term salivary effects of single-dose head and neck irradiation in the rat. Arch Oral Biol 43: 297-303, 1998.

PARIS F, FUKS Z, KANG A, CAPODIECI P, JUAN G, EHLEITER D, HAIMOVITZ-FRIEDMAN A, CORDONCARDO C, KOLESNICK R: Endothelial apoptosis as the primary lesion initiating intestinal radiation damage in mice. Science 293: 293-297, 2001.

PETER B, VAN WAARDE MA, VISSINK A, S-GRAVENMADE EJ, KONINGS AW: Radiation-induced cell proliferation in the parotid and submandibular glands of the rat. Radiat Res 140: 257-265, 1994.

PRICE RE, ANG KK, STEPHENS LC, PETERS LJ: Effects of continuous hyperfractionated accelerated and conventionally fractionated radiotherapy on the parotid and submandibular salivary glands of rhesus monkeys. Radiother Oncol 34: 39-46, 1995. 
ROSS GM: Induction of cell death by radiotherapy. Endocr Relat Cancer 6: 41-44, 1999.

ROOS G, LANDBERG G, HUFF JP, HOUGHTEN R, TAKASAKI Y, TAN EM: Analysis of the epitopes of proliferating cell nuclear antigen recognized by monoclonal antibodies. Lab Invest 68: 204-210, 1993.

SODICOFF M, CONGER AD, PRATT NE, TREPPER P: Radioprotection by WR-2721 against long-term chronic damage to the rat parotid gland. Radiat Res 76: 172-179, 1978.

STEPHENS LC, ANG KK, SCHULTHEISS TE, KING GK, BROCK WA, PETERS LJ: Target cell and mode of radiation injury in rhesus salivary glands. Radiother Oncol 7: 165-174, 1986.

TAYLOR SE: Efficacy and economic evaluation of pilocarpine in treating radiation-induced xerostomia. Expert Opin Pharmacother 4: 1489-1497, 2003.

TAYLOR SE, MILLER EG: Preemptive pharmacologic intervention in radiation-induced salivary dysfunction. Proc Soc Exp Biol Med 221: 14-26, 1999.

VITOLO JM, COTRIM AP, SOWERS AL, RUSSO A, WELLNER RB, PILLEMER SR, MITCHELL JB, BAUM BJ: The stable nitroxide tempol facilitates salivary gland protection during head and neck irradiation in a mouse model. Clin Cancer Res 10: 1807-1812, 2004.

\section{Reprint requests}

Jelena Tomac, Department of Histology and Embryology, Faculty of Medicine, University of Rijeka, B. Branchetta 20, 51000 Rijeka, Croatia. E-mail: jelenat@medri.hr 